\title{
Congenital Disorder of Glycosylation Type lj
}

National Cancer Institute

\section{Source}

National Cancer Institute. Congenital Disorder of Glycosylation Type Ij. NCI Thesaurus. Code C126874.

A congenital disorder of glycosylation sub-type caused by mutation(s) in the DPAGT 1 gene, encoding UDP-N-acetylglucosamine--dolichyl-phosphate Nacetylglucosaminephosphotransferase. 